\title{
Dimensões do sistema de escrita na formação de alfabetizadores
}

\author{
Sandra Mara Castro dos Santos ${ }^{1}$
}

Sandra Regina Kirchner Guimarães²

\begin{abstract}
Resumo
Investigou-se a presença de instruções relativas às habilidades metalinguísticas implicadas na aprendizagem da escrita, na formação continuada de professores proposta pelo Pacto Nacional Pela Alfabetização na Idade Certa. Participaram nove formadoras vinculadas ao PNAIC/UFPR, que responderam a um questionário contendo questões relativas ao material e à formação propostos. Os dados obtidos junto às participantes destacaram orientações explícitas para o desenvolvimento de habilidades metafonológicas, embora o trabalho seja voltado à manipulação de unidades suprafonêmicas nas palavras, sem focar no desenvolvimento da consciência fonêmica. Conclui-se que há necessidade de expansão de conteúdos referentes às habilidades metamorfológicas, metalexicais e metassintáticas, na formação.

Palavras-chave: Alfabetização; Sistema de escrita alfabética; Formação de professores; Habilidades metalinguísticas; PNAIC.
\end{abstract}

\section{Dimensions of the writing system in the training of literacy teachers}

\begin{abstract}
This study investigated the presence of instructions concerning metalinguistic skills that are implied in the learning of written language, in the material and training proposed by the National Pact for Literacy at the Correct Age (PNAIC). Nine teachers affiliated with the PNAIC/UFPR answered a structured questionnaire. Data reveal there are explicit instructions for the development of metaphonological skills, but all the suggestions are directed to the manipulation of supra-phonemic units in words, without focusing on activities intended to develop phonemic awareness. The conclusion is that there is a need to expand content concerning metamorphological, metalexical, and metasyntactic skills in the training of literacy teachers.

Keywords: Literacy; Writing system; Teachers training; Metalinguistic skills; PNAIC.
\end{abstract}

\section{Introdução}

A necessidade de se estudar a formação continuada dos professores brasileiros, em especial a ofertada pelo Ministério da Educação e Cultura (MEC), é justificada, entre outros fatores, pelos resultados das avaliações de larga escala.

O Indicador de Alfabetismo Funcional (INAF) ${ }^{3}$ (INAF BRASIL, 2018) - avalia o nível de

\footnotetext{
${ }^{1}$ Prefeitura Municipal de Curitiba. Endereço Eletrônico: sandsantos22@gmail.com

2 Universidade Federal do Paraná. Curitiba. Endereço Eletrônico: srkguimaraes@uol.com.br

${ }^{3}$ INAF - Indicador de Alfabetismo Funcional [realizado pelo Instituto Paulo Montenegro e pela ONG Ação Educativa]: focaliza habilidades de leitura e de escrita (letramento) e habilidades de cálculo e resolução de problemas 
alfabetização de pessoas entre 15 e 64 anos. Os resultados preliminares de 2018 revelaram que $29 \%$ da população de jovens e adultos pode ser considerada como analfabetos funcionais e $71 \%$ da população, funcionalmente alfabetizados. Somente $12 \%$ atinge um nível pleno de habilidades no uso da leitura, da escrita e da matemática. Já o IDEB ${ }^{4}$, em 2017, aferiu uma média nacional de 5,8 na Prova Brasil (BRASIL, 2018a), relativa aos anos iniciais do ensino fundamental, que ainda fica abaixo da mínima considerada adequada ao avanço de um ano escolar para outro (6,0 ou 7,0 em uma escala de 0 a 10). Esses dados mostram que a escola vem deixando a desejar na formação de leitores, o que se converte em prejuízos para o desenvolvimento individual dos alunos e da sociedade como um todo.

O ensino da leitura e da escrita requer professores que conheçam o processamento da aprendizagem nas crianças, o funcionamento do Sistema de Escrita Alfabética (SEA), bem como formas de trabalhar a estrutura e a funcionalidade da língua. Isso só é possível se receberem formação inicial e continuada condizente com os avanços da área produzidos cientificamente e com os advindos da experiência em sala de aula.

Em face dos baixos índices apresentados, vale questionar os motivos que levam a esses resultados, como as condições de trabalho, o número de alunos por turma, a falta de recursos humanos, a fragilidade nas formações ofertadas aos professores. No contexto das ações voltadas para a formação de professores, identifica-se a criação, pelo Ministério da Educação, desde 2013, do Pacto Nacional pela Alfabetização na Idade Certa (PNAIC) ${ }^{5}$, Programa focado na formação continuada de professores alfabetizadores, no qual universidades parceiras organizam cursos de formação de orientadores de estudo, selecionados pelas redes municipais e estaduais, para atuarem como multiplicadores diretamente com os referidos docentes.

(numeramento). Por meio da Teoria da Resposta ao Item (TRI), construiu-se uma escala única - a escala de alfabetismo - que integra ambas as habilidades (INAF BRASIL, 2018).

${ }^{4}$ IDEB - Índice de Desenvolvimento da Educação Básica: reúne dois conceitos importantes: fluxo escolar e médias de desempenho nas avaliações. Os resultados sintéticos permitem traçar metas de qualidade educacional para os sistemas. O indicador é calculado a partir dos dados sobre aprovação escolar e médias de desempenho nas avaliações do Inep, o Saeb - para as unidades da federação e para o país, e a Prova Brasil- para os municípios (BRASIL, 2018b).

${ }^{5}$ Pacto Nacional pela Alfabetização na Idade Certa (PNAIC): acordo formal assumido pelo Governo Federal, estados, municípios e entidades para firmar o compromisso de alfabetizar crianças até, no máximo, 8 anos de idade, ao final do ciclo de alfabetização (BRASIL, 2012a).

Periódico Horizontes - USF - Itatiba, SP-Brasil - e019002 
O presente trabalho, oriundo de dissertação, tem como objetivo analisar a formação continuada de professores alfabetizadores ofertada pelo PNAIC em Língua Portuguesa, tendo como base de análise a aprendizagem da língua escrita na perspectiva da Psicologia Cognitiva, em especial os estudos relativos às habilidades metalinguísticas, consideradas essenciais para a aprendizagem e aperfeiçoamento da linguagem escrita. Os pesquisadores que embasaram o estudo foram: Bradley; Bryant (1983); Bertelson et al. (1985); Olofsson; Lundberg (1985); Perfetti et al. (1987); Yavas (1988); Gombert (1992); Cardoso-Martins (1995); Byrne (1995); Demont (1997); Alégria; Leybaert; Mousty (1997); Maluf; Barrera (1997); Carlisle (2000); Guimarães (2003, 2005, 2011); Marec-Breton; Gombert (2004); Armengaud (2006); Mota; Silva (2007); Mota (2007); Mota, Annibal; Lima (2008); Barbosa (2008, 2013); Diniz (2008); Mota et al (2009); Correa (2009); Capovilla; Capovilla (2009); Santos; Maluf (2010); Paula; Leme (2010); Morais, A. (2012); Ehri; Boyer (2013); Siccherino (2013); Inácio; Mota (2013); Morais, J. (2014); Mota; Paula; Guimarães (2014); Correa; Dockrell; Zingier (2014); Godoy; Viana (2016).

\section{Habilidades cognitivas e linguísticas e o processo de alfabetização}

Habilidades metalinguísticas se referem à capacidade do indivíduo de analisar e refletir sobre a linguagem, controlando e planejando seus próprios processos linguísticos (YAVAS, 1988; DEMONT, 1997). Elas são imprescindíveis na aprendizagem e no aperfeiçoamento da escrita.

Refletir sobre as unidades sonoras das palavras promove a consciência fonológica que deve ser associada ao trabalho com as demais habilidades linguísticas - como os morfemas (consciência morfológica), estrutura dos enunciados (consciência sintática), intenção comunicativa (consciência pragmática) e gêneros textuais (consciência metatextual) (MORAIS, A. 2012).

Barbosa (2008), investigando relações entre habilidades metalinguísticas e a aprendizagem da escrita, observou professores durante o processo de ensino-aprendizagem da leitura e da escrita e verificou que eles dão mais importância ao aspecto fonológico em detrimento das demais habilidades metalinguísticas. Sugeriu, assim, que sejam repensados os currículos e conteúdos ofertados nas universidades aos alfabetizadores, bem como nas demais formações.

Periódico Horizontes - USF - Itatiba, SP-Brasil - e019002 
Considerando-se as habilidades metalinguísticas, tem-se que a consciência fonológica refere-se à capacidade de refletir acerca dos sons da fala (CARDOSO-MARTINS, 1995), abrangendo todos os seus segmentos (rimas, aliterações, sílabas, etc.). Já o termo consciência fonêmica se refere especificamente à reflexão sobre os fonemas.

Em uma perspectiva interativa, sustenta-se a existência de uma influência mútua entre ambos os fatores (BERTELSON et al., 1985; PERFETTI et al., 1987; ALÉGRIA; LEYBAERT; MOUSTY, 1997; DEMONT, 1997; BYRNE, 1995; GUIMARÃES, 2003). Sob essa ótica, a consciência fonológica contribui significativamente para os estágios iniciais da leitura e da ortografia, e estes, por sua vez, contribuem para o desenvolvimento de habilidades metafonológicas mais complexas, da consciência fonêmica (consciência da natureza psicologicamente segmentada da fala). Assim, a segmentação é um dos seus aspectos e a invariância, outro. De início, a criança associa a palavra ao seu significado, classificando-a em nível semântico, tendo dificuldade de pensá-la como corrente de som. O desenvolvimento da habilidade de decodificação na leitura e codificação na escrita depende de uma combinação de consciência fonêmica e correspondência entre letras e sons, e nenhum dos dois é suficiente por si mesmo (BYRNE, 1995). Segundo o autor, o trato com a consciência fonêmica deve ocorrer já na pré-escola, para facilitar o desenvolvimento progressivo da leitura e da escrita. Alguns pesquisadores defendem a instrução explícita em consciência fonêmica antes da alfabetização formal, para alunos da educação infantil (EHRI; BOYER, 2013; SICCHERINO, 2013).

Dessa forma, parece não haver dúvidas sobre a contribuição da consciência fonológica para a aprendizagem da escrita, porém, não há consenso acerca do momento escolar adequado à introdução de atividades para o desenvolvimento da consciência fonêmica. Pesquisadores, como Morais A. (2012), defendem trabalhos com rimas e aliterações, envolvendo unidades suprassilábicas, silábicas, subsilábicas, até chegar à percepção do fonema; outros defendem a utilização do ensino explícito para o desenvolvimento da consciência fonêmica por meio do método fônico, entre eles, Morais J. (2014).

Inácio e Mota (2013) analisaram o PNAIC e afirmam que o Programa, ao trazer a proposta de desenvolvimento da consciência fonológica, preenche uma lacuna na formação do professor alfabetizador, pois essa consciência trata de habilidade metalinguística relevante para a leitura 
e a escrita. Para elas, o Pacto, ao considerar todas as crianças capazes de aprender, defende que a alfabetização precisa se dar de forma significativa, em momentos de brincadeiras, jogos, músicas e cantigas não repetidas, mas pensadas, manipuladas, modificadas, ativas e vivas para todos os envolvidos neste processo - formadores, professores e estudantes. (INÁCIO; MOTA, 2013).

Com relação à consciência morfológica, entende-se que a escrita se materializa combinando dois tipos de princípios: o fonográfico e o semiográfico. O primeiro se refere à correspondência entre os grafemas e os fonemas ou sílabas, o segundo, ao fato de os grafemas representarem significados. O sistema ortográfico concretiza simultaneamente os níveis fonológico e morfológico da língua oral. Dessa forma, ambos são suscetíveis de desempenhar algum papel na aprendizagem da leitura. (MAREC-BRETON; GOMBERT, 2004).

A consciência morfológica refere-se à habilidade de refletir sobre os morfemas das palavras. À medida que o estudante se depara com vocábulos mais complexos, a consciência morfológica contribui para a leitura. A sensibilidade aos aspectos morfológicos, já que as palavras são formadas pela combinação de unidades mínimas - os morfemas -, pode contribuir para a habilidade de decodificação e promover a compreensão leitora - expandindo o vocabulário pela derivação de novas palavras a partir das já conhecidas e a definição de novas palavras, a partir do significado das partes constituintes (CORREA, 2009). O trabalho com a consciência morfológica pode contribuir para a alfabetização na medida em que um léxico mental vai se constituindo e pode ser acessado para compreensão de textos.

Estudos têm analisado a relação entre a consciência morfológica e o desempenho em leitura e(ou) escrita (MOTA; SILVA, 2007; MOTA, 2007; MOTA; ANNIBAL; LIMA, 2008; GUIMARÃES, 2003, 2005, 2011; BARBOSA, 2013). O último estudo citado investigou se o treinamento em morfologia pode influenciar o desempenho em ortografia e compreensão leitora. Para isso, a pesquisadora implementou um programa de intervenção para o ensino explícito de regras morfológicas, envolvendo a morfologia flexional e a derivacional, para 111 alunos do 40 ano (faixa etária de 9 a 10 anos), da rede pública do município de Curitiba. Os resultados mostraram aumento de desempenho na escrita de palavras que apresentavam os morfemas trabalhados explicitamente nas intervenções, comprovando que o ensino de regras 
morfológicas favorece a reflexão sobre os elementos linguísticos e o domínio pleno da escrita, no que se refere à ortografia. (BARBOSA, 2013).

Já a consciência sintática refere-se à habilidade de refletir, manipular e mostrar controle intencional sobre a sintaxe da língua (GOMBERT, 1992). Significa reconhecer que a linguagem possui um sistema de regras e combinar categorias gramaticais ou palavras entre si, de modo a produzir frases que tenham sentido. Esta habilidade favorece os processos de decodificação, de compreensão de leitura e de escrita. (DINIZ, 2008). A contribuição da consciência sintática e da morfossintática para o desenvolvimento da oralidade e da escrita tem motivado pesquisas no Brasil (GUIMARÃES, 2003, 2005, 2011; MOTA et al., 2009; DINIZ, 2008; MOTA; PAULA; GUIMARÃES, 2014).

Guimarães (2003) realizou uma investigação acerca do desempenho de crianças sem e com dificuldades de aprendizagem, utilizando três tarefas de avaliação da consciência fonológica e três de avaliação da consciência sintática/morfossintática, além de avaliar o desempenho na leitura e na escrita de palavras isoladas. No que se refere especificamente à consciência sintática/morfossintática, os resultados mostraram não haver diferenças significativas entre o desempenho dos estudantes dos Grupos 1 e 2 nas tarefas aplicadas, ou seja, os alunos do 4ㅇ e 50 ano com dificuldades de aprendizagem em leitura e escrita apresentaram desempenho

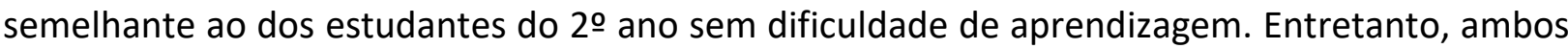
os grupos (1 e 2) apresentaram desempenho inferior ao do Grupo 3 (estudantes do 4ㅇ e 5으 ano sem dificuldade de aprendizagem). A autora concluiu que as habilidades medidas nas tarefas sintáticas/morfossintáticas são aperfeiçoadas com as experiências em leitura e escrita, e essas habilidades possibilitam aos estudantes maior domínio dos princípios ortográficos (morfossintáticos) relevantes na escrita.

Estudo realizado por Mota et al (2009) também demonstrou correlações entre medidas de consciência sintática e tarefas de escrita, sugerindo que a experiência das crianças no seu meio ambiente tem um papel significativo no desenvolvimento da consciência sintática.

Mota, Paula e Guimarães (2014), analisando pesquisas acerca do processamento morfológico e sua relação com o desenvolvimento da linguagem escrita, concluíram que a consciência morfológica é um constructo que contribui de forma consistente para a aquisição da 
leitura no português do Brasil. Salientaram que essa contribuição acontece desde a fase inicial da alfabetização, aumentando à medida que a criança avança no processo de escolarização. Destacaram também que as habilidades fonológicas e morfossintáticas começam a se desenvolver antes do processo formal de alfabetização. Além disso, argumentaram que dificuldades no processamento fonológico podem impedir os alunos de aproveitarem suas experiências em leitura e escrita para desenvolver a consciência morfossintática, sugerindo que os professores devem levar as crianças a refletirem acerca das estruturas fonológica e morfossintática das palavras.

Já a consciência lexical refere-se ao estabelecimento de critérios gramaticais para segmentar a linguagem. Quando a criança é capaz de segmentar, isolar ou quantificar a linguagem oral em palavras, reconhecendo primeiramente palavras com função semântica, como os substantivos, adjetivos e verbos, e posteriormente palavras com função sintática, como conjunções e preposições, diz-se que a criança desenvolveu o conceito de palavra e possui consciência lexical (DINIZ, 2008). Já a consciência semântica é relacionada à habilidade de reconhecer o sistema da linguagem como um código arbitrário e convencional. Como explica Armengaud (2006, p.12), a semântica "trata da relação dos signos, palavras e frases com as coisas e com os estados das coisas; é o estudo do conjunto do sentido, da referência e da verdade." Na opinião de Barbosa (2013), para conceituar uma palavra, o sujeito usa tanto a consciência lexical quanto a semântica.

Teoricamente, distingue-se consciência semântica e consciência lexical. Entretanto, os elementos do léxico constituem unidades mínimas de significado, dificultando a dissociação desses dois aspectos na observação do comportamento linguístico real (exceto talvez em estudos neuropsicológicos de indivíduos que manifestam problemas específicos em processos lexicais e semânticos) (GOMBERT, 1992).

Correa, Dockrell e Zyngier (2014), em estudo também realizado com crianças falantes do português, investigaram a ocorrência de hipersegmentação na escrita e o desenvolvimento do conceito de palavra morfológica. Analisando 72 narrativas de crianças do 1 으 ao 3 o ano, com grau de complexidade de acordo com a escolaridade, o estudo examinou a influência da fala nas hipersegmentações. As marcas da oralidade se fazem presentes nos anos iniciais nas 
hipersegmentações. A conclusão é de que a conceituação da palavra escrita se evidencia ao longo da escolarização, na participação em processo de ensino sistemático da língua, quando as crianças adquirem experiência com textos escritos. Nesse sentido, a consciência lexical e a consciência semântica também exercem influência sobre o desenvolvimento da leitura e da escrita.

Os estudos apresentados não deixam dúvidas acerca da importância do desenvolvimento das habilidades metalinguísticas para a alfabetização e compreensão leitora. Assim, um trabalho escolar efetivo deve ser realizado levando em conta o desenvolvimento da consciência fonológica, a aprendizagem das relações entre fonemas e grafemas e, concomitantemente e gradualmente, o desenvolvimento das demais habilidades metalinguísticas. A presente pesquisa investiga como esses conhecimentos foram incorporados na formação continuada dos professores alfabetizadores, proposta pelo Programa PNAIC.

\section{Metodologia}

Sendo poucas as investigações relacionadas à temática das habilidades metalinguísticas nos programas de formação docente, buscou-se, por meio de um enfoque qualitativo, explorar e descrever o programa de formação continuada PNAIC, com base em pesquisas recentes acerca da aprendizagem da leitura e da escrita na perspectiva da Psicologia Cognitiva.

O projeto que orienta a investigação foi aprovado pelo Comitê de Ética da Universidade Federal do Paraná (UFPR) - Setor de Ciências da Saúde, sob Registro CAAE: 30377414.3.0000.0102, Parecer 691.050.

As participantes da pesquisa foram nove formadoras vinculadas à coordenação do PNAIC na UFPR, responsáveis pela formação dos orientadores de estudo do polo de Curitiba. Os últimos atuaram com os professores alfabetizadores, constituindo assim a cadeia formativa.

Para a coleta dos dados, foram realizadas perguntas às formadoras, organizadas em um questionário, que tiveram como objetivo investigar a opinião das participantes acerca de uma variedade de temas e conteúdos ofertados aos professores alfabetizadores, em especial os relativos ao PNAIC na área de Língua Portuguesa. As perguntas foram elaboradas tendo como 
ênfase estudos e pesquisas empíricas relacionados à aprendizagem da língua escrita no enfoque da Psicologia Cognitiva. Na sua íntegra, as perguntas somam 7 blocos de análise. No presente artigo serão sistematizadas seis questões, respondidas por oito das nove participantes, referentes à opinião dessas formadoras acerca das habilidades metalinguísticas contempladas no material disponibilizado e da formação ofertada aos professores alfabetizadores.

Para a apresentação e discussão dos resultados, as respostas das participantes foram agrupadas por pergunta e por bloco, sendo comparadas e analisadas em razão do grau de concordância e/ou discrepância. A discussão dos resultados foi realizada de acordo com a revisão de literatura, buscando-se a opinião das formadoras com relação às problematizações.

\section{Resultados e discussão}

Apresentam-se os resultados referentes à presença de conteúdos concernentes às habilidades metalinguísticas na formação ofertada pelo PNAIC:

Na questão 1, perguntou-se às formadoras: No material do PNAIC são apresentadas orientações explícitas para o desenvolvimento das habilidades (meta) fonológicas? De que forma? Você considera estas orientações importantes? Por quê? As respostas foram organizadas em duas categorias, de acordo com as convergências observadas:

Primeira categoria: sete, das oito que responderam à questão, deram indicativos de que, no material ofertado para a formação continuada dos professores alfabetizadores, principalmente nas Unidades 3, são apresentadas orientações explícitas acerca da reflexão sobre os segmentos das palavras, possibilitando o desenvolvimento da consciência fonológica. As atividades propõem separar, contar e comparar os segmentos das palavras, refletindo sobre os segmentos sonoros envolvidos (rimas, segmentos compostos por mais de uma sílaba, segmentos maiores que um fonema e menores que uma sílaba, entre outros), considerando também a posição do segmento na palavra (início, meio, fim). Todas as respostas indicaram que essas orientações são importantes, principalmente para que o professor entenda a relevância do trabalho com a consciência fonológica e tenha subsídios para planejar intencionalmente atividades, visando à apropriação do SEA. Representando essa categoria, a formadora G afirma 
que esse trabalho é apresentado de forma a refletir junto aos alunos sobre as partes sonoras das palavras, considerando, entre outros, aspectos como as sílabas e letras, "orientações fundamentais para que o professor contemple atividades de consciência fonológica em seu planejamento, oportunizando, assim, a reflexão sobre o SEA" (formadora G).

Segunda categoria: duas formadoras indicam a necessidade de uma complementação no material do PNAIC com relação ao desenvolvimento metalinguístico como um todo. Ressaltam que, apesar de, no material, haver sugestões de atividades, como jogos, para o desenvolvimento dessas habilidades, essas não são esclarecedoras para quem não domina esse assunto. Conforme a formadora F, o tema é abordado "de forma superficial, não dando suporte necessário ao professor de compreender como desenvolver essas habilidades".

Assim, com relação ao desenvolvimento de habilidades (meta)fonológicas, as respostas à primeira questão indicaram a existência de orientações explícitas para o trabalho com as palavras (separar, contar e comparar segmentos). Essas orientações foram consideradas relevantes para que o professor compreenda a importância do trabalho com a consciência fonológica na aprendizagem do SEA e planeje atividades que desenvolvam essa habilidade.

Contudo, salienta-se a expressa necessidade de complementação do material de formação com atividades para o aprimoramento teórico-metodológico das demais atividades metalinguísticas apontada pelas respondentes. Salienta-se, ainda, que há divergências entre pesquisadores que estudam a relação consciência fonológica e aprendizagem da leitura e da escrita. Alguns defendem o trabalho com as unidades maiores da língua, como Morais A. (2012), e outros defendem o ensino explícito da consciência fonêmica já no início da alfabetização, como Morais J. (2014).

No caso do material de formação do PNAIC, observa-se que se dá ênfase às unidades fonológicas suprafonêmicas (rimas, aliterações, sílabas), apresentando indicações de trabalho implícito com os segmentos fonêmicos da fala em atividades com a letra inicial, por exemplo. Para Morais A. (2012), o trabalho com a notação escrita por si só facilita o desenvolvimento da consciência fonológica e da fonêmica, não sendo necessário um retorno aos antigos métodos fônicos. Segundo o autor, um trabalho de alfabetização com textos poéticos, cujas rimas, aliterações e outros recursos sonoros possibilitam a reflexão sonora sobre as palavras em jogos 
e atividades lúdicas, é indicado para a alfabetização.

$\mathrm{Na}$ questão 2, perguntou-se às formadoras: Existe um equilíbrio adequado entre as propostas de trabalho para o desenvolvimento da consciência fonológica - e consequente aprendizagem das relações biunívocas entre unidades sonoras e unidades gráficas - e o trabalho para o desenvolvimento de outras habilidades linguísticas (consciência morfológica, consciência sintática, por exemplo) que sustentam um maior domínio da leitura e escrita? As respostas possibilitaram a criação de duas categorias, com base na convergência ou divergência de opiniões:

Primeira categoria: concentram-se as respostas indicativas de que existe, no material ofertado para a formação, referencial teórico e metodológico relativo ao desenvolvimento da consciência fonológica, porém não há subsídios teóricos explícitos para o desenvolvimento das demais habilidades linguísticas. Dessa forma, o trabalho aparece implicitamente por meio de atividades envolvendo os gêneros textuais, de acordo com a formadora $\mathrm{H}$, "diluídas de forma mais geral [...], sempre que os textos dos Cadernos abordam referentes ao letramento, ao trabalho com gêneros textuais [...]". A formadora $\mathrm{G}$ expôs que algumas orientações do material sobre as consciências lexical, sintática, semântica e textual são "fracas", diante do fato de faltarem propostas de trabalho relacionadas à percepção de morfemas na constituição de palavras e à análise de sentenças para a compreensão da estrutura gramatical da língua e de, mesmo sendo garantido como direitos de aprendizagem, no eixo da escrita: "Gerar e organizar o conteúdo textual, estruturando os períodos e utilizando recursos coesivos para articular ideias e fatos" (BRASIL, 2012b, p. 34), não há relatos de atividades específicas para o desenvolvimento dessas habilidades, apenas sugestões de trabalho num contexto amplo.

A não unanimidade nas respostas possibilitou a criação da segunda categoria, visto que duas formadoras consideraram que o equilíbrio existe e se dá por meio de atividades, de acordo com as etapas do Ciclo. A formadora C justifica a afirmação apontando que "há diversos exemplos de atividades durante todo o material do PNAIC, principalmente respeitando as diferentes turmas de alfabetização".

Em síntese, a questão dois buscou investigar se há um equilíbrio entre o trabalho com a consciência fonológica e as demais habilidades metalinguísticas. As respostas foram divergentes. 
Seis formadoras consideraram que há um desequilíbrio na ênfase dada ao trabalho com a consciência fonológica em detrimento das demais habilidades, que receberiam um tratamento mais implícito, e duas consideraram que a abordagem e proporção de atividades estão adequadas. O que se depreende de suas respostas é que existe uma diferenciação gradativa no trabalho com os estudantes do 1으, 2으 e 3으 ano.

As respostas às primeiras questões corroboram os resultados de Barbosa (2008), que verificou a grande importância dada pelos professores ao aspecto fonológico da linguagem em detrimento das demais habilidades metalinguísticas. Esse resultado encontra explicação nos dados do estudo de Maluf, Zanella e Pagnez (2006), que constatam ser a consciência fonológica a habilidade metalinguística mais estudada no País (70,8\% das teses/dissertações e $77,3 \%$ dos artigos), enquanto a morfologia não encontra a mesma atenção no Brasil (4,4\% das dissertações e teses, e 4,5\% dos artigos publicados). Dessa forma, na presente pesquisa, evidencia-se a incorporação dos estudos acerca da consciência fonológica e de algumas referências à consciência morfológica, segunda mais citada no terceiro bloco de questões. Essa ênfase também pode ser explicada por meio de resultados de pesquisas empíricas (BERTELSON et al., 1985; PERFETTI et al., 1987; CARDOSO-MARTINS, 1995; DEMONT, 1997; MALUF; BARRERA, 1997; GUIMARÃES, 2003; SANTOS; MALUF, 2010; CAPOVILLA; CAPOVILLA, 2009) e de experiências realizadas em sala de aula que demonstram uma relação estreita entre a consciência fonológica e a alfabetização em diversas ortografias alfabéticas. Dessa forma, um equilíbrio referente ao desenvolvimento das habilidades metalinguísticas para a alfabetização poderia estar ligado a uma sistematização maior com relação à consciência fonológica no início da alfabetização, porém sem desconsiderar o trabalho progressivo com as demais habilidades metalinguísticas para o avanço e aperfeiçoamento dos conhecimentos linguísticos dos aprendizes, preocupação observada nos relatos das formadoras.

As demais questões investigam com mais ênfase a consciência morfológica e lexical (desenvolvimento do vocabulário e segmentação na escrita).

Na questão 3, perguntou-se às formadoras: Em situações de trabalho com segmentos sonoros que correspondem a afixos - por exemplo: o prefixo "re-" em palavras como: reusar, reciclar, reduzir, repensar e reapresentar - as atividades sugeridas destacam também o 
significado do morfema em questão? Essas atividades visam ao desenvolvimento do vocabulário receptivo (habilidade de compreender o que se ouve ou lê) e expressivo (habilidade de produzir palavras ou escrevê-las para se fazer entender) dos alunos? As respostas possibilitaram delimitar três categorias, considerando-se convergências e divergências nas opiniões:

1a categoria: sete das oito respondentes disseram que o material do PNAIC ofertado para a formação não contempla orientações explícitas para o trabalho com a morfologia derivacional e o desenvolvimento do vocabulário receptivo e expressivo.

2a categoria: três das respondentes deram indicativos da necessidade de complementação no material de orientações para o desenvolvimento da consciência morfológica, as quais elas ofertaram com outros materiais. A formadora A exemplifica o fenômeno com as propostas desenvolvidas para a abordagem dos processos de formação de palavras no português, em que foi ressaltado o uso de prefixos e sufixos, e da reflexão linguística acerca dos aspectos sintáticos e semânticos, além dos morfológicos. Para ela, há "reflexão sobre todos os elementos constitutivos desse objeto de investigação, num contínuo processo de aprender com a língua e sobre a língua".

3a categoria: duas formadoras consideraram que o material contempla atividades de reflexão que envolvem afixos e destacam o significado do morfema em questão, visando ao desenvolvimento do vocabulário, porém de forma implícita. A formadora C aponta, como exemplos, os Cadernos dos Anos 1 (azul), 2 (laranja) e 3 (verde) da Unidade 3, nos quais foram trabalhadas a apropriação do sistema de escrita alfabética e a consolidação do processo de alfabetização durante a formação.

Em síntese, as respostas indicaram que o material não contempla explicitamente trabalhos com a morfologia derivacional e o desenvolvimento do vocabulário receptivo e expressivo. Houve indicativos da necessidade de complementação durante a formação com orientações para o desenvolvimento da consciência morfológica, embora algumas respostas apontem a presença de propostas de trabalho com afixos e vocabulário receptivo e expressivo de forma implícita.

Verificou-se que algumas formadoras defendem o trabalho com a consciência morfológica já no início da alfabetização. O que está de acordo com Correa (2009), para quem a 
sensibilização com relação à morfologia pode contribuir em prol da habilidade de decodificação e promover a compreensão leitora, a expansão do vocabulário pela derivação vocabular, bem como a definição de novas palavras a partir do significado das partes constituintes. Considera-se que as respostas relativas ao desenvolvimento do vocabulário receptivo e expressivo foram vagas, mais relacionadas ao desenvolvimento de um léxico mental.

$\mathrm{Na}$ questão 4, perguntou-se às formadoras: Alguns alunos durante o processo de aprendizagem inicial e aperfeiçoamento da escrita empregam na composição do texto escrito características do português não padrão. Por exemplo: "as menina vai à festa"; "a gente vamos à festa". O material destinado à formação do PNAIC destaca a importância de um trabalho pedagógico que aborde questões relativas à morfossintaxe? Que encaminhamentos pedagógicos são sugeridos? As oito respostas foram organizadas em duas categorias:

Primeira categoria: em cinco respostas, ressaltou-se a ausência de um trabalho com a morfossintaxe que negligencia o Direito de Aprendizagem do eixo de análise linguística: "Usar adequadamente a concordância e reconhecer violações de concordância nominal e verbal" (BRASIL, 2012b, p. 36). Por isso, sugeriram-se complementações relacionadas ao trabalho com os gêneros textuais em atividades de leitura e de revisão dos textos. A formadora A chamou a atenção para a necessidade de desenvolver um trabalho consistente com as questões relativas à morfossintaxe ou à revisão textual, enfocando "a macroestrutura (conteúdo), a microestrutura (forma), a superestrutura (elementos constitutivos do gênero) e a autocorreção (revisão da escrita do vocabulário usado no texto)".

Segunda categoria: em seis das oito respostas, foram indicadas orientações para o trabalho com a morfossintaxe envolvendo o planejamento da alfabetização na perspectiva do letramento, a leitura de obras literárias na íntegra, o trabalho com os gêneros textuais e a revisão dos textos escritos pelos estudantes. A formadora $\mathrm{H}$ relata que, no eixo escrita, localizou apenas a sugestão de reescrita textual como possibilidade para o estudante se aperfeiçoar na funcionalidade e na adequação da escrita e, no eixo leitura, somente uma proposição de trabalho, quando se orienta o professor a ser fiel ao texto do autor, não substituindo a leitura pela contação, de modo a permitir a percepção das marcas da modalidade escrita, bem como há orientação para "o planejamento da leitura para propostas com textos mais longos, mais 
complexos, com vocabulário mais rebuscado, com estruturas sintáticas mais elaboradas".

Em síntese, a quarta questão relaciona-se à terceira por buscar quais orientações são dadas aos professores quando os estudantes, em processo inicial de alfabetização, não utilizam a norma padrão e acabam escrevendo com incorreções quanto à concordância verbal, por exemplo. Nesse caso, se há um trabalho voltado para a morfossintaxe. As respostas indicaram que não há no material de formação do PNAIC um trabalho explícito relacionado à morfossintaxe. Algumas formadoras indicaram a necessidade de complementações do material com a apresentação de atividades explícitas sobre como desenvolver as habilidades morfossintáticas. Essa recomendação encontra respaldo em Guimarães (2005), que investigou a influência da variação linguística e da consciência morfossintática nas diferenças de desempenho em leitura e escrita, em estudo no qual se mostrou que os níveis de variação linguística se correlacionam negativamente aos desempenhos em leitura e escrita, enquanto a consciência morfossintática se correlaciona positivamente. A autora sugere que os episódios de variação linguística não devem ser desconsiderados nem tratados como "linguagem errada", cabendo ao professor aproveitar para refletir acerca da variedade padrão, levando as crianças à tomada de consciência dos aspectos formais e estruturais da linguagem oral e sua relação com a escrita (GUIMARÃES, 2005).

Na questão 5, perguntou-se às formadoras: No material de formação do PNAIC há sugestões sobre como trabalhar com a normatização ortográfica, ou seja, é sugerida uma organização do ensino da ortografia de forma que o aluno possa aprender as regras para a escrita de palavras que apresentam correspondências regulares (diretas: relações biunívocas; contextuais: relação letra-som na posição da palavra e morfológico-gramaticais: regras que envolvem morfemas ligados à formação de palavras por derivação lexical ou flexional) e de como ensinar as palavras que apresentam correspondências irregularidades? Caso haja essas sugestões, você concorda com o trabalho proposto? As respostas permitiram a delimitação de duas categorias:

Primeira categoria: oito respondentes indicaram que no material do PNAIC há um trabalho voltado para a normatização ortográfica, principalmente nos Cadernos das Unidades 3. O Caderno do Ano 3, página 25, retoma os Direitos de Aprendizagem relacionados à 
normatização ortográfica, sendo indicado o trabalho com as correspondências regulares diretas e contextuais para o Ciclo I. Já a sistematização das correspondências regulares morfológicogramaticais e irregulares é indicada para o próximo ciclo. Também é sugerido que a reflexão acerca da norma ortográfica ocorra somente depois da apropriação do SEA, da efetivação da leitura e da produção de pequenos textos. $\mathrm{O}$ relato da formadora $\mathrm{H}$ ilustra a questão: $\mathrm{O}$ trabalho com as correspondências regulares diretas e contextuais envolve retirar palavras dos textos trabalhados, realizando-se o pareamento e comparação entre as sílabas; atividades e jogos com questões ortográficas relacionadas a essas correspondências; vivência diária dos estudantes com materiais impressos para que interajam com textos de boa qualidade e possam refletir sobre eles; atividades voltadas à reflexão sobre a norma ortográfica, envolvendo a escrita das palavras, analisando as regularidades existentes a partir de atividades relacionadas a regras ou à revisão dos textos escritos, com mediação docente. Três formadoras consideraram o trabalho indicado suficiente para o Ciclo de Alfabetização, porém disseram que não há impeditivos para reflexões acerca das correspondências morfológico-gramaticais e irregulares no contexto da sala de aula, de modo especial o contato com "os gêneros textuais possibilita a percepção de uma infinidade de palavras e o professor precisa estar preparado para refletir com os estudantes sobre as regularidades e suas exceções" (formadora $\mathrm{H}$ ).

Segunda categoria: concentram-se as respostas de seis formadoras que indicaram a necessidade de se complementar o trabalho de formação tanto com as correspondências regulares diretas e contextuais quanto com as morfológico-gramaticais e irregulares. A formadora A esclareceu que foram acrescentados à formação o trabalho com conceitos de consciência fonológica (princípio fonográfico), consciência fonêmica, consciência morfológica (princípio semiográfico), atividades práticas relacionadas às regularidades diretas: relações biunívocas; contextuais; relação letra-som na posição da palavra e morfológico-gramatical, dentre outras, orientando os alfabetizadores a vincular "o trabalho com um planejamento sistemático, a fim de promover reflexões junto às crianças sobre os princípios gerativos da língua" (formadora A). Dessa forma, não houve consenso acerca da suficiência do trabalho sugerido para a formação continuada do PNAIC, com relação à normatização ortográfica.

Em síntese, com relação à normatização ortográfica, as respostas à quinta questão 
indicaram que o material de formação contempla a organização do ensino da ortografia. No Ciclo I, o trabalho envolve as correspondências regulares diretas e contextuais e, no Ciclo II, a sistematização das correspondências morfológico-gramaticais e irregulares. Recomenda-se que o trabalho com tal normatização inicie após a apropriação do SEA pelo estudante. Porém, as respostas das formadoras não foram unânimes. Três consideram o trabalho adequado, e seis, insuficiente, necessitando de complementação teórica e metodológica tanto das correspondências diretas e contextuais quanto das morfológico-gramaticais e irregulares. Nesse sentido, Cagliari (1999) aponta a importância da aprendizagem da ortografia para fixar formas de escrita, já que pode evitar a confusão social causada por diferentes pronúncias das palavras, e isso ressalta a relevância da preocupação das formadoras com o ensino dessas normas.

Na questão 6, perguntou-se às formadoras: Como é proposto o trabalho para o ensino da segmentação da escrita em palavras gráficas no material do PNAIC? Há contribuição para a compreensão de que cada palavra se constitui unidade gráfica, com significado próprio no contexto em que está inserida?

As oito respondentes foram unânimes em considerar que o material do PNAIC traz indicações explícitas relacionadas ao trabalho com a segmentação na escrita, um dos Direitos de Aprendizagem. Isso envolve referenciais teóricos acerca do aprendizado do conceito abstrato de palavra - unidade gráfica - e a proposição de atividades para essa aprendizagem, como a indicação de jogos e outras atividades lúdicas envolvendo as propriedades do SEA. A formação possibilitou a revisão de algumas atividades comumente encontradas nos livros didáticos. No relato da formadora $\mathrm{H}$, apontam-se as sugestões de trabalho da Unidade 3, Ano 2, ressaltando que algumas propostas relacionadas aos livros didáticos foram repensadas com relação aos resultados das ações pedagógicas. Por exemplo, quando se solicita ao estudante pintar os espaços em branco de uma frase ou texto, este espaço deixou de ser vazio, configurando uma pintura e, "portanto, deixa de delimitar o início e fim de uma palavra, pois, para que as palavras sejam uma unidade de sentido, exigem espaços 'em branco'”. Nesse relato, destaca-se o trabalho com a ordenação e produção de frases em contextos significativos orientando a segmentação. Três formadoras abordaram a importância da atuação do professor para a efetivação do trabalho com essa segmentação. Entretanto, não houve menção a uma discussão sobre a diferença entre 
palavras lexicais e funcionais (BISOL, 2004).

Em síntese, as respostas à sexta questão, relacionada à consciência lexical, indicaram referências explícitas no material para o trabalho com a segmentação da escrita em palavras gráficas, cujos limites e significados são dados pelo contexto da frase, e, visando ao desenvolvimento da noção de palavra, o material propõe o uso de jogos e outras atividades lúdicas, envolvendo as propriedades do SEA.

\section{Conclusões e considerações finais}

O objetivo da pesquisa foi analisar a formação continuada de professores alfabetizadores ofertada pelo PNAIC em Língua Portuguesa, por meio da opinião das formadoras, que responderam às questões sobre o material e formação ofertados pelo PNAIC, com base na aprendizagem da língua escrita na perspectiva da Psicologia Cognitiva, em especial os estudos relativos às habilidades metalinguísticas, consideradas aqui essenciais para a aprendizagem e aperfeiçoamento da linguagem escrita.

Com relação à consciência fonológica, as orientações do material ofertado para a formação do PNAIC dão ênfase às unidades fonológicas suprafonêmicas (rimas, aliterações, sílabas). Observam-se, por exemplo, indicações de trabalho implícito com os segmentos fonêmicos da fala em atividades com a letra inicial. Essas orientações são relevantes, já que pesquisas comprovam a estreita relação entre a consciência fonológica e a aprendizagem da leitura e da escrita, possibilitando a compreensão do professor a respeito da necessidade de trabalho com essa habilidade em prol da aprendizagem do SEA e do planejamento de atividades relacionadas.

Ainda sobre esse aspecto, o estudo de Cardoso-Martins (1995) explica por que a habilidade de detectar rimas não é tão importante em português quanto no inglês, justifica que as rimas em inglês geralmente correspondem a segmentos menores que a sílaba, como ocorre nas palavras "tree" e "free". Já em português, em sua maioria, correspondem a segmentos maiores que a sílaba, como ocorre nas palavras "panela" e "janela". Nesse sentido, discriminar rimas em português não envolve necessariamente a habilidade de detectar pequenos segmentos 
intrassilábicos, o que seria mais importante para a aprendizagem inicial da leitura e da escrita.

No âmbito dessa temática, os estudos de Byrne e Fielding-Barnsley (1989) esclarecem que a compreensão do princípio alfabético requer três fatores: segmentar a língua em unidades distintas, conscientizar-se de que essas unidades se repetem em diferentes palavras e conhecer as regras de correspondência grafemas-fonemas.

Constata-se que a inclusão de subsídios teórico-metodológicos envolvendo a consciência fonológica foi um avanço na formação de professores, por incorporar conhecimentos essenciais à aprendizagem inicial da leitura e da escrita, e que há limitações, como a falta de referenciais específicos para o trabalho com consciência fonêmica. Várias pesquisas (EHRI; BOYER, 2013; SICCHERINO, 2013) defendem a instrução explícita da consciência fonêmica como relevante na aprendizagem da leitura e da escrita.

Nessa mesma direção, Godoy e Viana (2016), que também analisaram o PNAIC, afirmam que o material não leva em consideração o relatório Alfabetização infantil: os novos caminhos (BRASIL, 2007), que ressalta a importância da estimulação da consciência fonêmica e do ensino sistemático das correspondências grafema-fonema para facilitar a aprendizagem alfabética. Os dados obtidos nesta pesquisa corroboram o estudo das autoras, para quem "os conteúdos do PNAIC permanecem amparados pela teoria da psicogênese da escrita, eximindo-se de dar crédito às evidências da pesquisa científica no campo da leitura" (GODOY; VIANA, 2016, p.93).

Na realidade, parece não haver dúvidas sobre a necessidade de incluir, nos cursos de formação docente, conteúdos de consciência fonológica envolvendo diferentes segmentos sonoros, de modo a enfatizar as unidades suprafonêmicas - rimas, aliterações, sílabas, imprescindíveis à aprendizagem da escrita. No que diz respeito à consciência fonêmica, infere-se que a relutância à instrução explícita dessa habilidade parece estar ligada à preocupação com um retorno ao método tradicional fônico. Essa barreira deve ser rompida, incluindo na formação docente referenciais teórico-metodológicos relativos à consciência fonêmica e reforçando a concepção do alfabetizar letrando.

No que se refere às habilidades metalinguísticas, foi investigado se, no material ofertado para a formação do PNAIC, há equilíbrio no trabalho com cada uma delas, ou seja, se o trabalho para o desenvolvimento das habilidades metafonológicas aparece na mesma proporção do 
trabalho com as demais habilidades metalinguísticas. Identificaram-se opiniões divergentes. Houve tanto indicativos de desequilíbrio, privilegiando a consciência fonológica em detrimento das demais habilidades, que receberiam um tratamento mais implícito, quanto indicativos de que a abordagem e a proporção de atividades ligadas a ambas habilidades são adequadas. O que se depreende das respostas é uma diferenciação gradativa no trabalho com os estudantes do 1으, 2ํ e 3ำ ano. Talvez, esse maior número de atividades de consciência fonológica pode estar ligado ao fato de a formação ser indicada para o início da alfabetização, momento em que se dá a aprendizagem inicial da leitura e da escrita.

Assim, há sinais de que os cursos de formação docente devem incorporar os conhecimentos a respeito de todas as habilidades metalinguísticas. No Brasil, essa necessidade se confirma, por exemplo, nos depoimentos das formadoras que ressaltam não haver no PNAIC orientações explícitas para o trabalho com a morfologia derivacional e o consequente desenvolvimento do vocabulário. Essa lacuna foi suprida pelas formadoras com orientações de trabalho com a consciência morfológica e os princípios fonográfico e semiográfico, fato significativo, pois a sensibilização relativa à morfologia pode contribuir tanto para a habilidade de decodificação (MAREC-BRETON; GOMBERT, 2004) como para a promoção da compreensão leitora (CARLISLE, 2000). Além disso, destaca-se que as habilidades metamorfológicas permitem a expansão do vocabulário pela derivação de novas palavras a partir das já conhecidas e facilitam a definição de novas palavras a partir do significado das partes constituintes (CORREA, 2009).

Com relação ao trabalho com a normatização ortográfica, o material desenvolvido para a formação foi considerado um avanço por trazer uma proposta de organização do ensino da ortografia que propõe a sistematização das correspondências regulares diretas e contextuais no Ciclo I e a sistematização das correspondências morfológico-gramaticais e irregulares no Ciclo II. Recomenda-se o trabalho com a norma ortográfica após a apropriação do SEA pelo estudante e percebe-se mais sistematização no material do PNAIC com relação à ortografia. Porém, houve indicações de que a formação necessita de complementação teórica e metodológica tanto para as correspondências diretas e contextuais quanto para as morfológico-gramaticais e irregulares.

Já com relação às transgressões ortográficas, considerou-se adequado o trabalho indicado no material (atividades reflexivas, individuais e coletivas de textos produzidos; de 
utilização de jogos e outras atividades lúdicas para analisar palavras; de construção de regras por meio da observação do uso social da escrita e da exploração de dicionários).

É relevante entender que os conhecimentos trazidos pelos estudantes necessitam de complemento, substituição e atualização tanto na aprendizagem inicial como no aperfeiçoamento da escrita, e isso requer o ensino da ortografia, que, na língua portuguesa, não é totalmente transparente, havendo necessidade de se ensinar as regras e irregularidades da língua, para que essas sejam aprendidas conscientemente e utilizadas adequadamente na escrita (PAULA; LEME, 2010). Em suma, no trabalho com a ortografia, deve-se considerar o conhecimento que o estudante possui e proceder ao ensino explícito, relacionado às regularidades e irregularidades da linguagem escrita.

Com relação à consciência lexical, há referências explícitas no material de formação para o trabalho com a segmentação da escrita em palavras gráficas, cujos limites e significados são dados pelo contexto. Com vistas ao desenvolvimento da noção de palavra, o material propõe o uso de jogos e outras atividades lúdicas que abarquem as propriedades do SEA. As orientações sobre o conceito abstrato de palavra e as atividades para a compreensão dessas como unidades gráficas, considerando o significado de acordo com o contexto, estão de acordo com uma proposta que visa ao desenvolvimento da consciência lexical. Porém, não houve indicativos de orientações teóricas a esse respeito - como, por exemplo, explanações sobre as diferenças entre as palavras de conteúdo e as palavras de forma ou gramaticais -, que possibilitariam um trabalho mais consciente por parte do professor alfabetizador.

Em síntese, embora o material ofertado para a formação do PNAIC tenha trazido um expressivo avanço em relação aos programas anteriores, verificou-se a ausência de subsídios teóricos e metodológicos explícitos que focalizem o desenvolvimento de diferentes habilidades metalinguísticas entre os estudantes. Entretanto, dado o expressivo número de estudos sustentando o papel destas habilidades na aprendizagem da língua escrita, aponta-se a necessidade de intensificar a inserção desses conteúdos na formação dos professores alfabetizadores para que possam auxiliar os estudantes a desenvolverem um nível pleno de habilidades no uso da leitura e da escrita. 


\section{Referências}

ALÉGRIA, J.; LEYBAERT, J.; MOUSTY, P. Aquisição da leitura e distúrbios associados: avaliação, tratamento e teoria. In: GREGÓIRE, J; PIÉRART, B. Avaliação dos problemas de leitura: os novos modelos teóricos e suas implicações diagnósticas. Trad. Maria Regina Borges Osório. 1.ed. Porto Alegre: Artes Médicas, 1997. p. 105-124.

ARMENGAUD, F. A pragmática. Trad. de Marcos Marcionilo. São Paulo: Parábola, 2006.

BARBOSA, V. R. Estudo comparativo entre as concepções teóricas e a prática pedagógica de professores alfabetizadores. 2008. 197f. Dissertação (Mestrado em Educação) - Universidade Federal do Paraná, Curitiba, 2008.

BARBOSA, V. R. O papel da consciência morfológica no aperfeiçoamento da linguagem escrita. 2013. 243f. Tese (Doutorado em Educação) - Programa de Pós-Graduação em Educação da Universidade Federal do Paraná, Curitiba, 2013.

BERTELSON, P.et al. Phonetic analysis capacity and learning to read. Nature, v. 313, p. 73-74, jan. 1985.

BISOL, L. A palavra prosódica e a morfologia e suas repercussões no ensino. In: 56a reunião anual da SBPC, Cuiabá, MT, jul. 2004. Anais...Cuiabá, MT. Disponível em:

http://www.sbpcnet.org.br/livro/56ra/banco_conf_simp/textos/LedaBisol.htm. Acesso em: 18 jul. 2015.

BRASIL. Grupo de trabalho alfabetização infantil: os novos caminhos: relatório final. 2. ed. Brasília: Câmara dos Deputados, Coordenação de Publicações, 2007.

BRASIL. INEP (Instituto Nacional de Estudos e Pesquisas Anísio Teixeira). IDEB: resultados e metas. 2017. Disponível em: http://ideb.inep.gov.br/resultado/. Acesso em: 15 out. 2018a.

BRASIL. Ministério da Educação. Ideb Apresentação. Disponível em: http://portal.mec.gov.br/conheca-o-ideb. Acesso em: 28 fev. $2018 \mathrm{~b}$.

BRASIL. Pacto Nacional pela Alfabetização na Idade Certa: caderno de apresentação. Brasília: MEC, SEB, 2012a.

BRASIL. Pacto Nacional pela Alfabetização na Idade Certa. Currículo na Alfabetização: concepções e princípios. Ano 1, Unidade 1. Brasília: MEC, SEB, 2012b.

BRADLEY, L.; BRYANT, P. Categorizing sounds and learning to read: a causal connection. Nature, V.301, p. 419-421, 1983.

Periódico Horizontes - USF - Itatiba, SP-Brasil - e019002 
BYRNE, B. Treinamento da consciência fonêmica em crianças pré-escolares: por que fazê-lo e qual seu efeito? In: CARDOSO-MARTINS, C. Consciência fonológica e alfabetização. 1. ed. Petrópolis: Vozes, 1995. p. 37-67.

BYRNE, B.; FIELDING-BARNSLEY, R. Phonemic awareness and letter knowledge in the child's acquisition of the alphabetic principle. Journal of Educational Psychology, v.81, n.3, p.313-321, 1989.

CAGLIARI, L. C. Alfabetizando sem o bá-bé-bi-bó-bu. 1. ed. São Paulo: Scipione, 1999.

CAPOVILLA, A. G. S.; CAPOVILLA, F. C. A consciência fonológica e sua importância para a aquisição da linguagem escrita. In: MOTA, M. M. P. (Org.). Desenvolvimento metalinguístico: questões contemporâneas. 1. ed. São Paulo: Casa do Psicólogo, 2009. p. 19-40.

CARDOSO-MARTINS, C. Consciência fonológica e alfabetização.1. ed. Petrópolis: Vozes, 1995.

CARLISLE, J. Awareness of the structure and meaning of morphologically complex words: impact on reading. Reading andWriting: anInterdisciplinaryJournal, v.12, p.169-190, 2000.

CORREA, J. Habilidades metalinguísticas relacionadas à sintaxe e à morfologia. In: MOTA, M. M. P. (Org.). Desenvolvimento metalinguístico: questões contemporâneas. 1. ed. São Paulo: Casa do Psicólogo, 2009. p. 55-76.

CORRÊA, J.; DOCKRELL, J.; ZYNGIER, S. A ocorrência de hipersegmentações na escrita e o desenvolvimento do conceito de palavra morfológica. In: ROAZZI, A.; PAULA, F. V.; SANTOS, M. J. Leitura e escrita: a sua aprendizagem na teoria e na prática. 1. ed. Curitiba: Juruá, 2014. p. 41-54.

DEMONT, É. Consciência fonológica, consciência sintática: que papel (ou papéis) desempenha na aprendizagem da leitura? In: GRÉGOIRE, J.; PIÉRART, B. Avaliação dos problemas de leitura: os novos modelos teóricos e suas implicações diagnósticas. Trad. Maria Regina Borges Osório. 1. ed. Porto Alegre: Artes Médicas, 1997. p.189-201.

DINIZ, N. L. B. Metalinguagem e alfabetização: efeitos de uma intervenção para recuperação de alunos com dificuldades na aprendizagem da linguagem escrita. 2008. 260f. Tese (Doutorado em Psicologia Escolar e do Desenvolvimento Humano) - Universidade de São Paulo, São Paulo, 2008.

EHRI, L.; BOYER, N. Contribution of phonemic segmentation instruction with letters and articulation pictures to word reading and spelling in beginners. Disponível em: https://eric.ed.gov/?id=EJ933946.Acesso em: 13 maio 2014.

GODOY, D. M. A.; VIANA F. L. Conteúdos linguísticos como subsídio à formação de professores 
alfabetizadores: a experiência Brasil e Portugal. Revista Brasileira de Estudos Pedagógicos, v.97, n.245, p.93, 2016.

GOMBERT, J-E. Metalinguistic development. Chicago: University of Chicago Press, 1992.

GUIMARÃES, S. R. K. Dificuldades no desenvolvimento da lectoescrita: o papel das habilidades metalinguísticas. Psicologia: teoria e pesquisa, v.19, n.1, p.33-45, 2003.

GUIMARÃES, S. R. K. Influência da variação linguística e da consciência morfossintática no desempenho em leitura e escrita. Interação em Psicologia. v.9, n.2, p.261-271, 2005.

GUIMARÃES, S. R. K. Relações entre capacidade de segmentação lexical, consciência morfossintática e desempenho em leitura e escrita. Psicologia: teoria e pesquisa, v.27, n.1, p.23-32, 2011.

INÁCIO, D. P.; MOTA, M. M. P. Consciência fonológica e alfabetização: algumas reflexões sobre o PNAIC. In: CAGNIN, S.; PAIVA, M. G. (Orgs.). Temas atuais em psicopedagogia. Rio de Janeiro: Letra Capital, 2013, p.13-24.

INAF BRASIL 2018. Indicador de alfabetismo funcional: resultados preliminares. Disponível em: https://drive.google.com/file/d/1ez-6jrlrRRUm9JJ3MkwxEUffltjCTEI6/view. Acesso em: 15 out. 2018.

MALUF, M. R.; BARRERA, S. D. Consciência fonológica e linguagem escrita em pré-escolares. Psicologia: Reflexão e Crítica, v.10, n.1, 1997. p. 0.

MALUF, M. R.; ZANELLA, M. S.; PAGNEZ, K. S. M. M. Habilidades metalinguísticas e linguagem escrita nas pesquisas brasileiras. Boletim de Psicologia, v.LVI, p.67-92, 2006.

MAREC-BRETON, N.; GOMBERT, J.E. A dimensão morfológica nos principais modelos de aprendizagem da leitura. In: MALUF, M. R. (Org.). Psicologia educacional: questões contemporâneas. 1. ed. São Paulo: Casa do Psicólogo, 2004, p.105-121.

MORAIS, A. G. Sistema de escrita alfabética (como eu ensino). 1. ed. São Paulo: Melhoramentos, 2012.

MORAIS, J. Alfabetizar para a democracia. 1. ed. Porto Alegre: Penso, 2014.

MOTA, M. M. P. Complexidade fonológica e reconhecimento da relação morfológica entre as palavras: um estudo exploratório. Psic (São Paulo), v.8,n.2, p.131-138, 2007.

MOTA, M. M. P.; SILVA, K. Consciência morfológica e desenvolvimento ortográfico: um estudo exploratório. Psicologia em Pesquisa, v.1, n.2, p.86-92, jul./dez. 2007. 
MOTA, M. M. P.; ANNIBAL, L.; LIMA, S. A morfologia derivacional contribui para a leitura e escrita do português? Psicologia: Reflexão e Crítica, v.21,n.2, p.311-318, 2008.

MOTA, M. M. P.et al. Consciência morfossintática, alfabetização e contextos do desenvolvimento. Psico-USF, v.14, n.1, p.11-18, jan./abr. 2009.

MOTA, M. M. P.; PAULA, F. V.; GUIMARÃES, S. R. K. Processamento morfológico e linguagem escrita: o que as pesquisas brasileiras apontam. In: ROAZZI, A.; PAULA, F. V.; SANTOS, M. J. (Orgs.). Leitura e escrita: a sua aprendizagem na teoria e na prática. Curitiba: Juruá, 2014.p. 55-66.

OLOFSSON, A.; LUNDBERG, I. Evaluation of long term effects of phonemic awareness training in kindergarten: illustrations of some methodological problems in evaluation research. Scandinavian Journal of Psychology, v.26, p.21-34, 1985.

PAULA, F. V.; LEME, M. I. S. Aprendizagem implícita e explícita: uma visão integradora. Psicologia em Pesquisa, v.4, n.1, p.15-23, jan./jun. 2010.

PERFETTI, Charles et al. Phonemic knowledge and learning to read are reciprocal: a longitudinal study of first grade children. Merrill-Palmer Quarterly, v. 33, p.283-319, 1987.

SANTOS, M. J.; MALUF, M. R. Consciência fonológica e linguagem escrita: efeitos de um programa de intervenção. Educar em Revista, Curitiba, Brasil, n. 38, p.57-71, set./dez. 2010.

SICCHERINO, L. A. F. Primeiras fases da alfabetização: como a intervenção em consciência fonêmica ajuda as crianças na aprendizagem inicial da leitura. 2013. 240 f. Tese (Doutorado em Educação: Psicologia da Educação) - Pontifícia Universidade Católica de São Paulo, 2013.

YAVAS, F. Habilidades metalinguísticas na criança: uma visão geral. Cadernos de Estudos Linguísticos, Campinas, v.14, p.39-51, jan./jun. 1988.

Recebido em outubro de 2017.

Aprovado em outubro de 2018. 